\section{Lymphozyten, gereizte}

\section{H. Baum}

Institut für Laboratoriumsmedizin, Mikrobiologie und Blutdepot, Regionale Kliniken Holding RKH GmbH, Ludwigsburg, Deutschland

\section{Synonym(e) Virozyten}

\section{Englischer Begriff virocyte}

Definition Große transformierte Lymphozyten bei Virusinfektionen.

Die Abbildung zeigt einen gereizten Lymphozyten, charakteristisch ist auch die Anschmiegung des Zytoplasmasaums an die Erythrozyten $(1000 \times$, May-Grünwald-GiemsaFärbung):

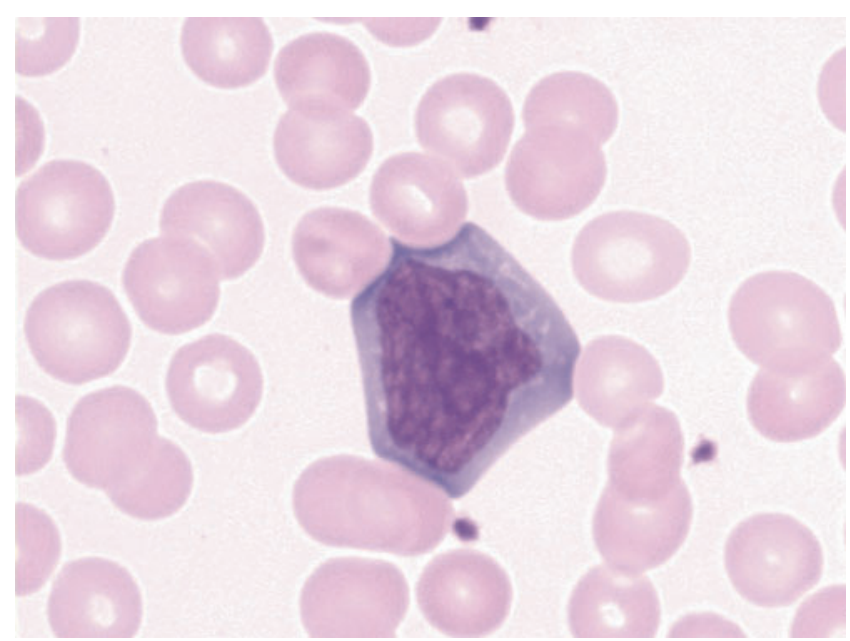

Beschreibung Gereizte Lymphozyten sind morphologisch darstellbare größere Lymphozyten (s. \ Lymphozyt) mit einem verbreiterten hell- bis dunkelbasophilen Zytoplasmasaum und häufig feiner azurophiler Granulation. Der Nachweis dieser transformierten Lymphozyten im peripheren Blut ist ein Hinweis auf einen viralen Infekt, wobei differenzialdiagnostisch in erster Linie eine Toxoplasmose, Rubeolen, Hepatitiden und eine EBV-Infektion infrage kommen. Gereizte Lymphozyten mit dunklerem, breiterem Zytoplasmasaum, die an Plasmazellen erinnern, werden als Türck'sche Reizformen bezeichnet. Differenzialdiagnostisch muss auch an eine Leukose gedacht werden, da die transformierten Zellen morphologisch Blasten ähneln können.

\section{Literatur}

Theml H, Diem H, Haferlach T (2002) Taschenatlas der Hämatologie, 5. Aufl. Georg Thieme Verlag, Stuttgart, S 66-69 